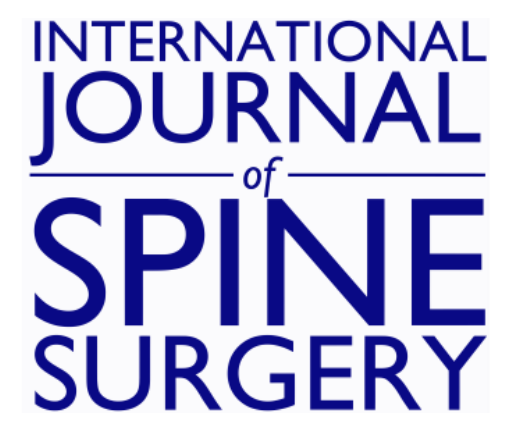

\title{
Tethered Cord as a Complication of Chronic Cerebral Spinal Fluid Diversion
}

Nitin Agarwal, David R. Hansberry and Ira M. Goldstein

Int J Spine Surg 2017, 11 (4)

doi: https://doi.org/10.14444/4026

http://ijssurgery.com/content/11/4/26

This information is current as of April 26, 2023.

Email Alerts Receive free email-alerts when new articles cite this article. Sign up at:

http://ijssurgery.com/alerts 


\section{Tethered Cord as a Complication of Chronic Cerebral Spinal Fluid Diversion}

Nitin Agarwal, MD,1,2 David R. Hansberry, MD, Ph.D, ${ }^{2}$ Ira M. Goldstein, $M D^{2}$

${ }^{1}$ Department of Neurological Surgery, University of Pittsburgh Medical Center, Pittsburgh, Pennsylvania, ${ }^{2}$ Department of Neurological Surgery, Rutgers New Jersey Medical School, Newark, New Jersey

\section{Abstract}

\section{Introduction}

The etiology and treatment of tethered cord syndrome remains controversial, especially in adults. We present an unusual case of tethered cord syndrome with an associated epidural lipomatosis likely due to chronic over shunting of cerebrospinal fluid (CSF).

\section{Methods}

A 25-year-old woman had a history of Chiari malformation, hydrocephalus, and a ventriculoperitoneal shunt. She demonstrated progressively worsening gait, which led to a diagnosis of myelopathy and a posterior cervical decompression and fusion was performed. Imaging revealed engorgement of the epidural veins ventral to the spinal cord which was causing cord compression. Magnetic resonance (MR) imaging of the lumbar spine demonstrated a lowlying conus at the level of L2-L3 with an absence of CSF in the lumbar cistern. This was associated with this was a widening of the epidural space with secondary epidural lipomatosis. She underwent a laminectomy of L5 as well as decompression of the inferior aspect of the L4 and superior aspect of the S1 lamina. No free flow of CSF could ever be appreciated as was suggested by postoperative MR imaging. Postoperatively, the patient did well and was discharged in stable condition.

\section{Conclusion}

Tethering of the spinal cord, associated with epidural lipomatosis, may be secondary to over-drainage of CSF. Symptoms of back pain and tethered cord phenomenon may warrant surgical intervention.

LUMBAR SPINE

KEYWORDS: TETHERED CORD, VENTRICULOPERITONEAL SHUNT, ARACHNOIDITIS, EPIDURAL LIPOMATOSIS

VOLUME 11 ISSUE 4 DOI: 10.14444/4026

PAGES $208-211$

\section{Introduction}

Tethered cord syndrome (TCS), first coined in 1976 by Hoffman et al., occurs due to an abnormal stretching of the spinal cord due to tissue attachments which limit the movement of the spinal cord. ${ }^{1}$ Posttraumatic and post-surgical scarring are among the secondary causes of TCS. ${ }^{2}$ Clinical findings associated with TCS in children include cutaneous stigmata, hair patches, or fatty tumors of the lower back. Neurologic symptoms lower extremity weakness, low back pain, scoliosis, and urinary incontinence or retention. ${ }^{3}$ TCS may not become apparent until the onset of more conspicuous symptoms in adulthood such as bilateral lower extremity motor and sensory loss; bowel and bladder incontinence; and severe pain. ${ }^{4}$ The authors present the first case of spinal cord tethering secondary to cerebral spinal fluid (CSF) over-drainage, resulting in a dry lumbar cistern with an associated engorgement of the epidural veins and epidural lipomatosis.

\section{Clinical Presentation}

A 25-year-old woman had a history of Chiari malformation, hydrocephalus, and long history of VP shunt. She demonstrated myelopathic findings and magnetic resonance (MR) imaging of the cervical spine demonstration engorgement of the ventral epidural veins with cord compression (Figure 1). She underwent a posterior decompression and fusion in 2008 to address her cervical compression. Since then has had progressive worsening of her gait. She continued to experience spasticity, right lower extremity weak- 
ness, ataxic gait, and urinary retention without incontinence of bowel or bladder. MR imaging of the lumbar spine demonstrated a low-lying conus at the level of L2-3 with an absence of CSF in the lumbar cistern (Figure 2). Ventral venous engorgement and marked dorsal epidural lipomatosis was evident throughout the lumbar spine as well.

She underwent a laminectomy of L5 as well as decompression of the inferior aspect of the L4 and superior aspect of the S1 lamina. Copious epidural lipomatosis was encountered. A markedly narrowed thecal sac was seen after decompression of the epidural

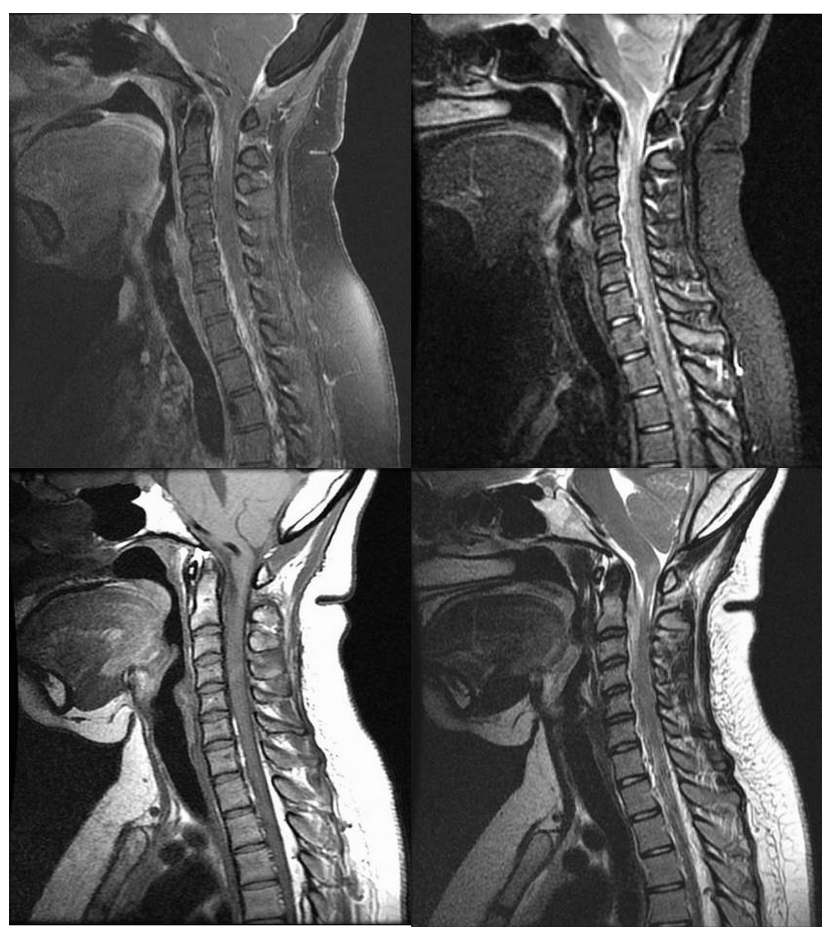

Fig. 1. (Top Left) Preoperative MRI Cervical Spine Sagittal $T_{1}$ with constrast. (Top Right) MRI Cervical Spine Sagittal STIR. (Bottom Left) MRI Cervical Spine Sagittal $\mathrm{T}_{1}$ without constrast. (Bottom Right) MRI Cervical Spine Sagittal $\mathrm{T}_{2}$.
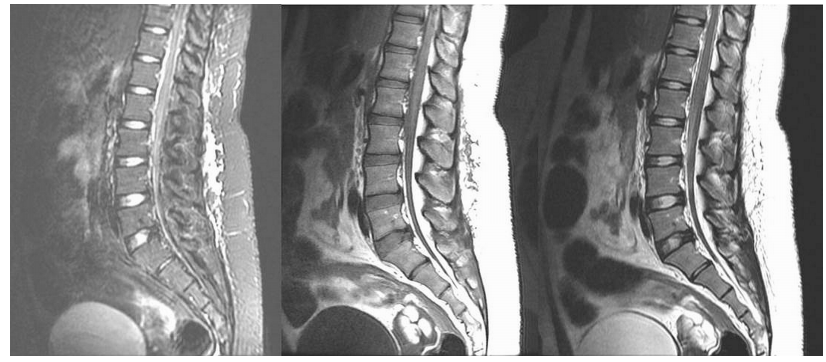

Fig. 2. Preoperative (Left) MRI Lumbar Spine Sagittal STIR. (Middle) MRI Lumbar Spine Sagittal $T_{1}$. (Right) MRI Lumbar Spine Sagittal $T_{2}$. lipomatosis via resection and bipolar electrocautery. Somatosensory evoked potentials, motor evoked potentials, and electromyography (EMG) monitoring were stable throughout the operation. Upon opening the dura, there was no CSF encountered, instead observed was a markedly thickened arachnoid with multiple adhesions between the arachnoid plane and spinal cord (Figure 3). Despite the thecal sac being opened and epidural lipomatosis being debrided, the markedly thickened arachnoid layer and the absence of visible CSF verified the dry thecal sac was a primary condition rather than the result of extrinsic compression. In addition, the nerve roots appeared to be clumped amongst themselves by an adhesive arachnoiditis. In the midline a slightly thickened filum was encountered. The nerve roots were then dissected free from one another using blunt dissection with micro instruments. Dissection was carried out rostrally, but free flow of CSF could never be appreciated as suggested by postoperative MR imaging (Figure 4). Triggered EMGs were utilized to demonstrate the filum, which was cauterized and sectioned. Multiple layer closure was performed to complete the operation. Postoperatively, the patient did well and was discharged in stable condition.

\section{Conclusion}

Chronic over-drainage has been associated with a variety of conditions including: cervical myelopathy, chronic headaches, subdural hematoma, post-shunt craniosynostosis, and slit ventricle syndrome. Subdural hematoma occurs when bridging veins between

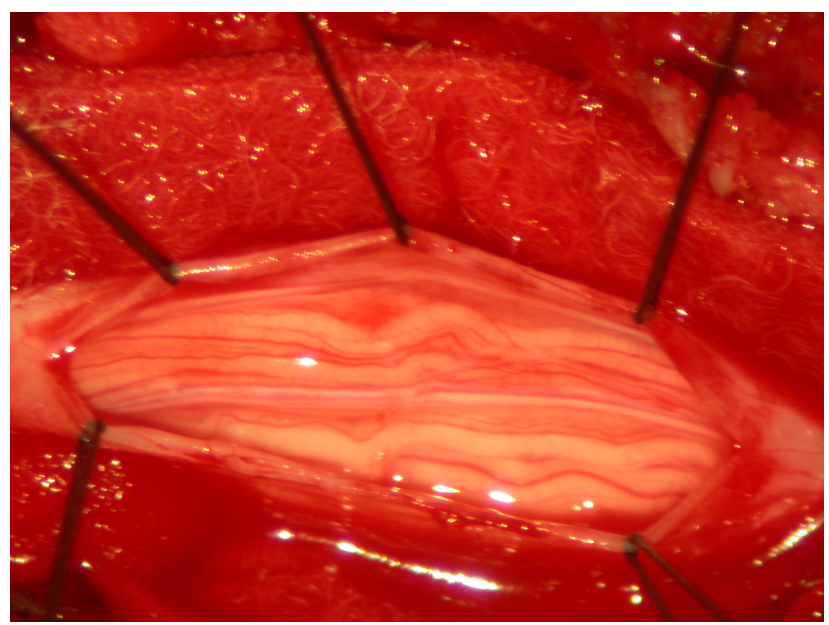

Fig. 3. Intraoperative of thecal sac contents, demonstrating clumped nerve roots with absence of CSF.

Downloaded from http://ijssurgery.com/ by guest on April 26, 2023 
the brain and skull tear as a resulting of excessive stretching. In an infant, post-shunt craniosynostosis may result after decompression of hydrocephalus resulting in overlapping of the cranial sutures. Slit ventricle syndrome is typically observed following chronic shunting and is characterized by recurring headaches. Treatment options for chronic overshunting include placement of a programmable valve, using a valve with an anti-syphon device, as well as third ventriculostomy. ${ }^{5}$ The authors present the first reported case of spinal cord tethering as a complication of chronic CSF over-drainage.

Conceivable alternative etiologies for a dry thecal sac include: a fistula, proximal pseudomeningocele, prior lumbar surgery, significant inflammatory process, and major lumbar trauma. Onuki et al. have suggested that during the third trimester of gestation a decrease in lumbosacral CSF volume may be observed. ${ }^{6}$ Silverberg et al. have reported a decreased production rate in dementia of the Alzheimer's type. Dry lumbar punctures have also been reported in cases with an epidural abscess. ${ }^{8}$ However, none of the aforementioned conditions were present in this patient. Moreover, the patient did not have a syrinx, dry cervical thecal sac, or descent of the cerebellar tonsils resulting in CSF flow obstruction. While Milhorat et al. have suggested there may be a link between a Chiari I malformation and tethered cord,' several studies have suggested against such an association. ${ }^{10-12}$ Thereby, the authors attribute the dry lumbar thecal sac to chronic CSF over-drainage.

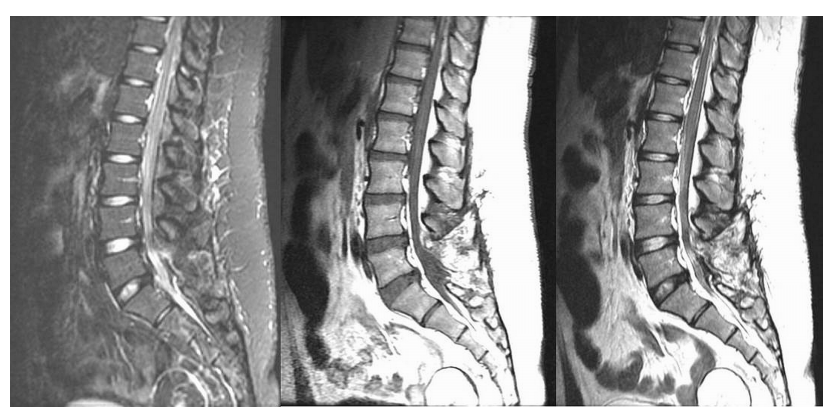

Fig. 4. Postoperative (Left) MRI Lumbar Spine Sagittal STIR. (Middle) MRI Lumbar Spine Sagittal $\mathrm{T}_{1}$. (Right) MRI Lumbar Spine Sagittal $\mathrm{T}_{2}$.

\section{Risk Factors and Treatment for}

\section{Epidural Lipomatosis}

With regards to epidural lipomatosis, obesity and glucocorticoid use are known risk factors. ${ }^{13-15}$ Additionally, idiopathic cases of spinal epidural lipomatosis have also been documented. Spinal epidural lipomatosis is more common in the thoracic region but also can be found in the lumbar region. ${ }^{16}$ Treatment of epidural lipomatosis is poorly defined; however, treatment can be tailored to the suspected underlying cause, if known. ${ }^{17}$ If obesity is the suspected cause, weight loss is recommended. Similarly, if the epidural lipomatosis is caused by steroid use, it is recommended to wean the patient off them, if possible. In addition, surgical intervention with decompressive laminectomy and resection, particularly in patients with lumbar epidural lipomatosis can be therapeutic. ${ }^{17}$ This patient is not obese or on steroid therapy, and as such, the authors propose the presence of epidural lipomatosis is due to a condition of chronic hypotension within the lumbar spinal canal.

\section{TCS Treatment}

In the setting of clinical signs or symptoms of deterioration, detethering is a reasonable therapeutic strategy. For most cases a single surgery will suffice, symptoms of tethering may recur with growth. Recovery of lost motor or bowel and bladder function typically depends on the degree and length of preoperative issues. Perioperative complications have been reported to occur with a frequency of approximately 1 to 2 percent. These issues may include infection, bleeding, or damage to the spinal cord. Release of the tethered spinal cord in cases of prior trauma or surgery carries greater risk secondary to adherence of the spinal cord to an area of scarring as opposed to a neurologically inert filum terminale. Unfortunately, the standard treatment for TCS that presents in adulthood remains controversial. ${ }^{18}$ As observed in this case, adults with TCS more often present with pain and less often with bladder dysfunction compared to children with TCS. ${ }^{19}$ Düz et al. have suggested that surgical intervention may be discussed in the context of a patient who has an inactive lifestyle and intolerable symptoms during the day; however, in pa- 
tients without a pattern of progression who have tolerable symptoms, surgical interventions should not be advised regardless of activity level. ${ }^{18}$ Given our patient's deteriorating state, surgical intervention was warranted and performed with positive clinical outcomes.

\section{References}

1. Hoffman HJ, Hendrick EB, Humphreys RP. The tethered spinal cord: its protean manifestations, diagnosis and surgical correction. Childs Brain 1976;2:145-155.

2. Hertzler DA, DePowell JJ, Stevenson CB, Mangano FT. Tethered cord syndrome: a review of the literature from embryology to adult presentation. Neurosurgical Focus 2010;29:E1.

3. Lew SM, Kothbauer KF. Tethered cord syndrome: an updated review. Pediatr Neurosurg 2007;43:236-248.

4. Hertzler DA, 2nd, DePowell JJ, Stevenson CB, Mangano FT. Tethered cord syndrome: a review of the literature from embryology to adult presentation. Neurosurg Focus 2010;29:E1.

5. Pople IK. Hydrocephalus and Shunts: What the Neurologist Should Know. Journal of Neurology, Neurosurgery \& Psychiatry 2002;73:i17-i22.

6. Onuki E, Higuchi H, Takagi S, Nishijima K, Fujita N, Matsuura T, et al. Gestation-related reduction in lumbar cerebrospinal fluid volume and dural sac surface area. Anesth Analg 2010;110:148-153.

7. Silverberg GD, Heit G, Huhn S, Jaffe RA, Chang $\mathrm{SD}$, Bronte-Stewart $\mathrm{H}$, et al. The cerebrospinal fluid production rate is reduced in dementia of the Alzheimer's type. Neurology 2001;57:1763-1766.

8. Sahu DK, Kaul V, Parampill R. "Dry tap" during spinal anaesthesia turns out to be epidural abscess. Indian J Anaesth 2012;56:287-290.

9. Milhorat TH, Bolognese PA, Nishikawa M, Francomano CA, McDonnell NB, Roonprapunt C, et al. Association of Chiari malformation type I and tethered cord syndrome: preliminary results of sectioning filum terminale. Surg Neurol 2009;72:20-35.

10. Massimi L, Peraio S, Peppucci E, Tamburrini G, Di Rocco C. Section of the filum terminale: is it worthwhile in Chiari type I malformation? Neurol Sci 2011;32 Suppl 3:S349-351.
11. Steinbok P, MacNeily AE. Section of the terminal filum for occult tethered cord syndrome: toward a scientific answer. Neurosurg Focus 2007;23:E5.

12. Valentini LG, Selvaggio G, Visintini S, Erbetta A, Scaioli V, Solero CL. Tethered cord: natural history, surgical outcome and risk for Chiari malformation 1 (CM1): a review of 110 detethering. Neurol Sci 2011;32 Suppl 3:S353-356.

13. Haddad SF, Hitchon PW, Godersky JC. Idiopathic and glucocorticoid-induced spinal epidural lipomatosis. J Neurosurg 1991;74:38-42.

14. Chan JY, Chang CJ, Jeng CM, Huang SH, Liu YK, Huang JS. Idiopathic spinal epidural lipomatosis - two cases report and review of literature. Chang Gung Med J 2009;32:662-667.

15. Rajput D, Srivastava AK, Kumar R. Spinal epidural lipomatosis: An unusual cause of relapsing and remitting paraparesis. J Pediatr Neurosci 2010;5:150-152.

16. Payer M, Van Schaeybroeck P, Reverdin A, May D. Idiopathic symptomatic epidural lipomatosis of the lumbar spine. Acta Neurochirurgica 2003;145:315-321.

17. Fassett DR, Schmidt MH. Spinal epidural lipomatosis: a review of its causes and recommendations for treatment. Neurosurgical Focus 2004;16:1-3.

18. Duz B, Gocmen S, Secer HI, Basal S, Gonul E. Tethered cord syndrome in adulthood. J Spinal Cord Med 2008;31:272-278.

19. Akay KM, Ersahin Y, Cakir Y. Tethered cord syndrome in adults. Acta Neurochir (Wien) 2000;142:1111-1115.

\section{Disclosures \& COI}

The authors declare no relevant financial disclosures or conflicts of interest.

\section{Corresponding Author}

Ira M. Goldstein, M.D. 90 Bergen Street, Suite 8100 , PO Box 1709, Newark, NJ, goldstir@njms.rutgers.edu.

Published 4 August 2017.

This manuscript is generously published free of charge by ISASS, the International Society for the Advancement of Spine Surgery. Copyright @ 2017 
ISASS. To see more or order reprints or permissions, see http://ijssurgery.com. 